\title{
The Effect of Zeolite Composition and Grain Size on Gas Sensing Properties of $\mathrm{SnO}_{2} /$ Zeolite Sensor
}

\author{
Yanhui Sun ${ }^{1,2} \mathbb{1}^{\mathbb{D}}$, Jing Wang ${ }^{1, *}$, Xiaogan $\mathrm{Li}^{1, *}$, Haiying Du ${ }^{1,3}$, Qingpan Huang ${ }^{1}$ and \\ Xiaofeng Wang ${ }^{4}$ \\ 1 Faculty of Electronic Information and Electrical Engineering, Dalian University of Technology, Dalian 116024, \\ China; syh@dlnu.edu.cn (Y.S.); duhaiying@dlnu.edu.cn (H.D.); huangqingpan@mail.dlut.edu.cn (Q.H.) \\ 2 College of Information \& Communication Engineering, Dalian Minzu University, Dalian 116600, China \\ 3 College of Mechanical and Electronic Engineering, Dalian Minzu University, Dalian 116600, China \\ 4 School of Mathematical and Physical Sciences, Dalian University of Technology, Panjin Campus, \\ Panjin 124000, China; wangxf@dlut.edu.cn \\ * Correspondence: wangjing@dlut.edu.cn (J.W.); lixg@dlut.edu.cn (X.L.); \\ Tel.: +86-411-8470-8382 (J.W.); Fax: +86-411-8470-6706 (J.W.)
}

Received: 19 December 2017; Accepted: 24 January 2018; Published: 29 January 2018

\begin{abstract}
In order to improve the sensing properties of tin dioxide gas sensor, four kinds of different $\mathrm{SiO}_{2} / \mathrm{Al}_{2} \mathrm{O}_{3}$ ratio, different particle size of MFI type zeolites (ZSM-5) were coated on the $\mathrm{SnO}_{2}$ to prepared zeolite modified gas sensors, and the gas sensing properties were tested. The measurement results showed that the response values of $\mathrm{ZSM}-5$ zeolite $\left(\mathrm{SiO}_{2} / \mathrm{Al}_{2} \mathrm{O}_{3}=70\right.$, grain size $\left.300 \mathrm{~nm}\right)$ coated $\mathrm{SnO}_{2}$ gas sensors to formaldehyde vapor were increased, and the response to acetone decreased compared with that of $\mathrm{SnO}_{2}$ gas sensor, indicating an improved selectivity property. The other three ZSM-5 zeolites with $\mathrm{SiO}_{2} / \mathrm{Al}_{2} \mathrm{O}_{3} 70,150$ and 470, respectively, and grain sizes all around $1 \mu \mathrm{m}$ coated $\mathrm{SnO}_{2}$ sensors did not show much difference with $\mathrm{SnO}_{2}$ sensor for the response properties to both formaldehyde and acetone. The sensing mechanism of ZSM-5 modified sensors was briefly analyzed.
\end{abstract}

Keywords: gas sensor; zeolite; tin dioxide; selectivity; catalytic property; coating

\section{Introduction}

Formaldehyde is an important chemical industrial material and organic solvent and it is widely used in wood processing, the textile industry and in other fields. Formaldehyde is also a kind of harmful gas. Excessive inhalation of formaldehyde in the body can cause discomfort in the eyes and nose. Prolonged time spent in a formaldehyde environment will lead to the occurrence of cancer. A standard of $0.08 \mathrm{ppm}$ averaged over $30 \mathrm{~min}$ for long-term exposure in formaldehyde vapor has been established by the World Health Organization (WHO) [1]. In recent years, more and more bodily harm occurs because of the excessive levels of formaldehyde which exist in the renovation materials and furniture. The monitor and control of indoor air pollution are attracting much attention recently [2-5]. Conductivity measurement using the semiconductor gas component is a common method of gas concentration detection. Gas sensors made of metal oxides possess good sensing properties such as high sensitivity, short response and recovery times and low cost. Tin dioxide is a kind of common metal oxide gas sensing material. $\mathrm{SnO}_{2}$ gas sensor can react with the electron of the gas, then the electrons are bound by the adsorbed oxygen. This decreases the conduction electrons in surface space-charge region of N-type material, so the resistance of the material is high. When tin dioxide meets reducing gas, the gas will react with adsorbed oxygen and release the oxygen-binding electronic. As a result, the surface electrical conductivity increases and the resistance of the material decreases [6]. Because the $\mathrm{SnO}_{2}$ has an adsorption capacity to many organic gases, the poor selectivity is an inherent problem. The $\mathrm{SnO}_{2}$ sensor has good response for many VOCs gases, such as methanol [7], ethanol [8], formaldehyde [9], 
acetone [10], etc. A lot of research has focused on how to improve the selectivity of gas sensors. Various methods including temperature control, doping noble metal and addition of filter layer may be used to improve sensor selectivity [11-16]. Among them, the addition of filter layer is the lowest cost and most convenient method.

Zeolites are kinds of aluminosilicates crystalline materials. They are built up with $\mathrm{SiO}_{4}$ and $\mathrm{AlO}_{4}$ tetrahedra, which form three-dimensional (3D) frameworks with linked channel systems and well-defined micropores and mesopores $[17,18]$. Zeolites possess molecular sieve property; they can make the gas molecules with smaller size pass through the zeolites channels and block the bigger molecules [19]. Utilizing the zeolites as a physical filter layer, zeolites can effectively improve selectivity of some semiconductor gas sensors. Many researches have focused on the application of zeolite as a physical filter layer in the sensitive material. For example, thick film sensors were prepared by screen printing layers of chromium titanium oxide (CTO) and tungsten trioxide with A-type zeolite, Y-type zeolite and ZSM-5 zeolite as over-layers, respectively, and the target gases were two similar gases: ethanol and isopropyl alcohol. The response of the CTO/H-A sensor to isopropyl alcohol (IPA) was suppressed by the A-type zeolite layer because of the molecular sieving effect [20]. Similarly, the $\mathrm{WO}_{3}$ and H-ZSM-5 composites can be printed onto an aluminum substrate to enhance the selectivity of $\mathrm{NO}_{2}$ [21]. Micromachined sensors was prepared by A-type zeolite microdropping on the $\mathrm{Pd}$ doped $\mathrm{SnO}_{2}$ sensitive material. The measurement results showed that the responses for some gases were suppressed, such as $\mathrm{CO}, \mathrm{H}_{2}, \mathrm{CH}_{4}, \mathrm{C}_{3} \mathrm{H}_{8}$, but the response for ethanol was not changed [22]. The selectivity of $\mathrm{SrTi}_{1-x} \mathrm{Fe}_{x} \mathrm{O}_{3-\delta}$ sensor to propane was improved by zeolite Pt-MFI modified [23]. The selectivity of $\mathrm{La}_{2} \mathrm{O}_{3}-\mathrm{Au} / \mathrm{SnO}_{2}$ sensor to $\mathrm{CO}$ was improved after it was modified using zeolite FER [24].

Zeolites possess both molecular sieve and catalytic properties. Normally, the molecular sieve property of zeolite was used to improve the selectivity of composite materials [25,26], and the catalytic property was often used to increase the response to target gas $[15,27]$. It is generally believed that the process of target gas molecules passing through the zeolite layer to the sensitive material is as follows [15,28]: (1) The target gas diffused into the pore channel of the zeolite and reached the catalytic active sites; (2) The gas molecules were adsorbed on the catalytic active sites (acidic sites); (3) A series of catalytic reactions occurred between the gas molecules and the acid sites of the zeolite and produced the catalytic by-products; (4) The reaction products deactivated from the active sites and spread out from the zeolite channel, and then reached to the surface of the sensitive material. In this process, the number of catalytic active sites (acidic sites) in zeolite plays an important role. In general, the number of zeolitic acidic sites decreases with the increase of $\mathrm{SiO}_{2} / \mathrm{Al}_{2} \mathrm{O}_{3}$ ratio. The reduction of zeolite grain size also leads to an increase in the zeolite specific surface area and pore volume. However, the increase of pore volume will further increase its acidic sites and thus increase its catalytic activity $[29,30]$.

Based on the above considerations, this report focuses on the effect of the gas sensing characteristics about different $\mathrm{SiO}_{2} / \mathrm{Al}_{2} \mathrm{O}_{3}$ ratio and different grain size of $\mathrm{ZSM}-5$ as the adding layer on $\mathrm{SnO}_{2}$ sensors to improve the sensor's sensing properties. The research about the effect of the grain size of the zeolite on the gas sensing properties were rarely reported in previous literature. In addition, numerous research has focused on the detection of $\mathrm{CO}, \mathrm{H}_{2}, \mathrm{NO}_{2}$ and other target gases [21,24,31,32], and there were few reports about the research of detecting formaldehyde using this type of gas sensors.

\section{Experimental}

\subsection{ZSM-5 Zeolite Preparation}

Four kinds of ZSM-5 zeolites have been used in this study, small particle size, low $\mathrm{SiO}_{2} / \mathrm{Al}_{2} \mathrm{O}_{3}$ ratio of ZSM-5 zeolite (named MFI-S); $\mathrm{SiO}_{2} / \mathrm{Al}_{2} \mathrm{O}_{3}$ ratio of $\mathrm{ZSM}-5$ zeolites were 70, 150 and 470 (named MFI-70, MFI-150 and MFI-470), respectively. The latter three kinds of zeolites were purchased from the Catalyst Plant of Nankai University, Tianjin, China. The MFI-S zeolite was prepared by hydrothermal synthesis following template method in our laboratory [33]. Silica source (TEOS) and 
$\mathrm{NaOH}$ purchased from Tianjin Kemiou Chemical Reagent Co., Ltd. (Tianjin, China), aluminum source (aluminum isopropoxide) purchased from Tianjin Guangfu Fine Chemical Research Institute (Tianjin, China), template agent (TPAOH) purchased from Sinopharm Chemical Reagent Co., Ltd. (Shanghai, China), respectively. The typical synthesis procedure was as follows: The predetermined amount of deionized water was added into $25 \%$ TPAOH aqueous solution to make a $15.7 \% \mathrm{TPAOH}$ aqueous solution $(50 \mathrm{~g})$, which was stirred with deionized water $(16 \mathrm{~g})$ and $1.12 \mathrm{~g} \mathrm{NaOH}$ for $10 \mathrm{~min}$ till the solution became clear. Then, $0.27 \mathrm{~g}$ aluminum isopropoxide was poured into the clear solution and kept stirring for $5 \mathrm{~h}$ to get transparent solution. After that, $32 \mathrm{~mL}$ TEOS was mixed with the transparent solution and kept stirring $12 \mathrm{~h}$ and the resulting mixture was transferred into a Teflon-lined stainless-steel autoclave and heated at $100{ }^{\circ} \mathrm{C}$ for $12 \mathrm{~h}$. Then the temperature increased to $180{ }^{\circ} \mathrm{C}$ and crystallization continued for $12 \mathrm{~h}$. The resultant solid product was separated from the mother liquor by centrifugation. After cooling, the mixture was centrifuged at $4000 \mathrm{rpm}$ for $30 \mathrm{~min}$ to discard the supernatant. The predetermined amount of deionized water was added into the centrifuge tube and made the solid disperse in the deionized water by ultrasonic vibration for $10 \mathrm{~min}$. The above procedure was repeated twice. Then, the sample was washed again with ethanol. Afterwards, the samples were dried at $100^{\circ} \mathrm{C}$ for $2 \mathrm{~h}$ followed by calcination at $550{ }^{\circ} \mathrm{C}$ for $6 \mathrm{~h}$. The temperature rising rate was $2^{\circ} \mathrm{C} / \mathrm{min}$.

\subsection{Characterization}

The structures of the ZSM- 5 zeolites were characterized by an X-ray diffraction instrument (XRD: D/Max 2400, Rigaku, Japan) in $2 \theta$ region of $3-60^{\circ}$ at a rate of $6^{\circ} / \mathrm{min}$ with $\mathrm{Cu} \mathrm{K} \alpha$ radiation. The morphology images of ZSM-5 zeolites and cross-sectional SEM image of ZSM- 5 coated $\mathrm{SnO}_{2}$ sensor were obtained by using field emission scanning electron microscope (FE-SEM: Hitachi S-4800, Tokyo, Japan). The ratio of $\mathrm{SiO}_{2} / \mathrm{Al}_{2} \mathrm{O}_{3}$ for the four kinds of $Z \mathrm{ZM}-5$ zeolites were measured by Coupled plasma atomic emission spectrometer (ICP-OES: Optima 2000 DV, PerkinElmer, Waltham, MA, USA).

\subsection{Sensors Fabrication and Measurements}

The $\mathrm{SnO}_{2}$ were mixed with deionized water to form a paste. The paste was coated onto a clean ceramic tube with electrodes and wires to form a sensing film, and then annealed at $400{ }^{\circ} \mathrm{C}$ for $2 \mathrm{~h}$ in air. Four kinds of ZSM-5 zeolite were also mixed with deionized water to form pastes, respectively, and coated outside of the $\mathrm{SnO}_{2}$ sensors to form four kinds of ZSM- 5 coated $\mathrm{SnO}_{2}$ gas sensors (MFI-S, MFI-70, MFI-150 and MFI-470). The final ceramic tube was annealed at $400{ }^{\circ} \mathrm{C}$ for $2 \mathrm{~h}$ in air, and then a Ni-Cr resistor wire was threaded through the tube as a heater. Finally, the electrode and heater wires were welded on a base element to form inside-heated gas sensors. $\mathrm{The}_{\mathrm{SnO}} \mathrm{O}_{2}$ sensor used for comparison with ZSM- 5 coated $\mathrm{SnO}_{2}$ sensors in this work was fabricated by the above method. The $\mathrm{SnO}_{2}$ powder was purchased from Sinopharm Chemical Reagent Co., Ltd. The $\mathrm{SnO}_{2}$ nanoparticles were relatively uniform with average grain size of $\sim 10 \mathrm{~nm}$.

The static state gas sensing characterization system was used to measure the gas sensing properties of the above sensors. The structure diagram of the static state gas sensing characterization is shown in Figure 1. The gas sensors were placed in a test chamber with a volume of $50 \mathrm{~L}$. A given amount of target gas solution was injected into a heated crucible in the test chamber by micro injector, then, it was uniformly distributed throughout the test chamber driven by two fans. In a gas desorption process, the test chamber was opened and the element was exposed to the air. The export voltage of the gas sensor is measured by a voltage dividing circuit that realized by series of gas sensor and divider resistance $R_{\mathrm{L}}$. The test voltage loaded at the voltage dividing circuit is $10 \mathrm{~V}$. By replacing the divider resistance $R_{\mathrm{L}}$, the beginning voltage $\left(V_{\text {air }}\right)$ of the divider resistor $R_{\mathrm{L}}$ is controlled at $8-9 \mathrm{~V}$, and the voltage of the gas sensor is $1-2 \mathrm{~V}$. According the resistance value of divider resistance $R_{\mathrm{L}}$ and the voltage value of the divider resistance $\left(V_{\text {gas }}\right)$, the sensor response $(S)$ to the test gas is calculated as $S=R_{\mathrm{a}} / R_{\mathrm{g}}$, and $R_{\mathrm{a}}=R_{\mathrm{L}}\left(10-V_{\text {air }}\right) / V_{\text {air }}, R_{\mathrm{g}}=R_{\mathrm{L}}\left(10-V_{\text {gas }}\right) / V_{\text {gas }}$. Where $R_{\mathrm{a}}$ and $R_{\mathrm{g}}$ are resistance of the sensor in air and in target gas, respectively [34]. 


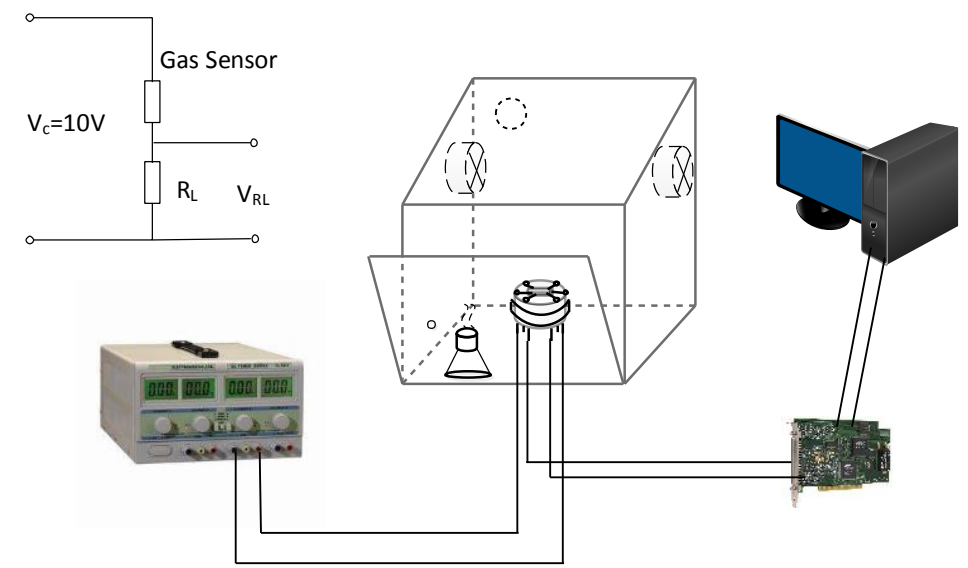

Figure 1. Structure diagram of gas sensing characterization system.

\section{Results and Discussion}

\subsection{Materials Characterization}

The X-ray diffraction patterns (XRD) of the zeolites that used in the study are shown in Figure 2. The XRD of the samples showed the peaks corresponding to the ZSM-5 type zeolite. These four kinds of materials have the same characteristic peaks, indicating that the four materials have the same structure.

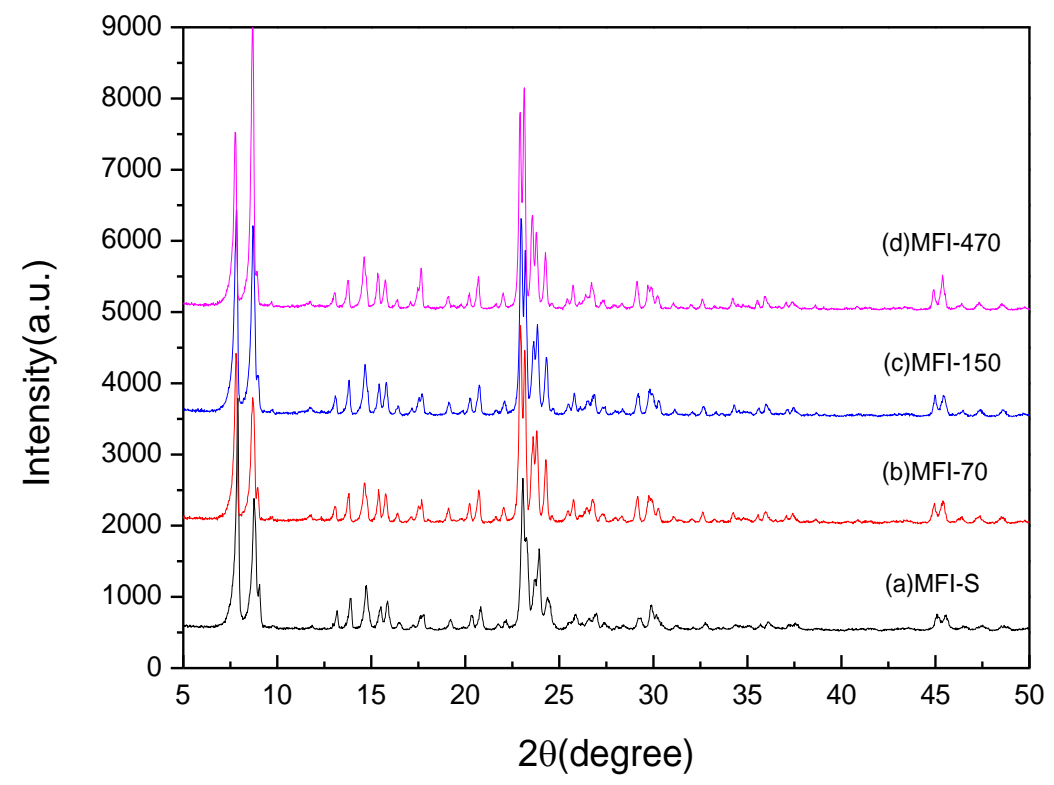

Figure 2. XRD patterns of (a) MFI-S (b) MFI-70 (c) MFI-150 and (d) MFI-470.

Figure 3a-d gives the SEM images of the four kinds of ZSM-5 zeolite samples. We can see from Figure 3 that the zeolites crystal lines are relatively uniform and the surfaces of the particles are relatively smooth. The average grain size of MFI-S $(300 \mathrm{~nm})$ is much smaller than these of other three samples $(\sim 1 \mu \mathrm{m})$. The average grain size of the latter three samples are nearly the same. Figure 4 shows the cross-sectional SEM image for ZSM- 5 coated $\mathrm{SnO}_{2}$ sensor. The thicknesses of $\mathrm{SnO}_{2}$ sensitive and ZSM- 5 coated layers are around $15 \mu \mathrm{m}$ and $20 \mu \mathrm{m}$, respectively.

The ratio of $\mathrm{SiO}_{2} / \mathrm{Al}_{2} \mathrm{O}_{3}$ for the four kinds of ZSM- 5 zeolites were measured by Coupled plasma atomic emission spectrometer. Table 1 lists the $\mathrm{SiO}_{2} / \mathrm{Al}_{2} \mathrm{O}_{3}$ ratio and the grain size of four kinds of zeolite. It can be seen from Table 1 that the $\mathrm{SiO}_{2} / \mathrm{Al}_{2} \mathrm{O}_{3}$ ratio of MFI-S is the same as the MFI-70, but 
the grain size is quite different. The grain size of MFI-70, MFI-150 and MFI-470 are similar, but the ratio of $\mathrm{SiO}_{2} / \mathrm{Al}_{2} \mathrm{O}_{3}$ increases gradually.
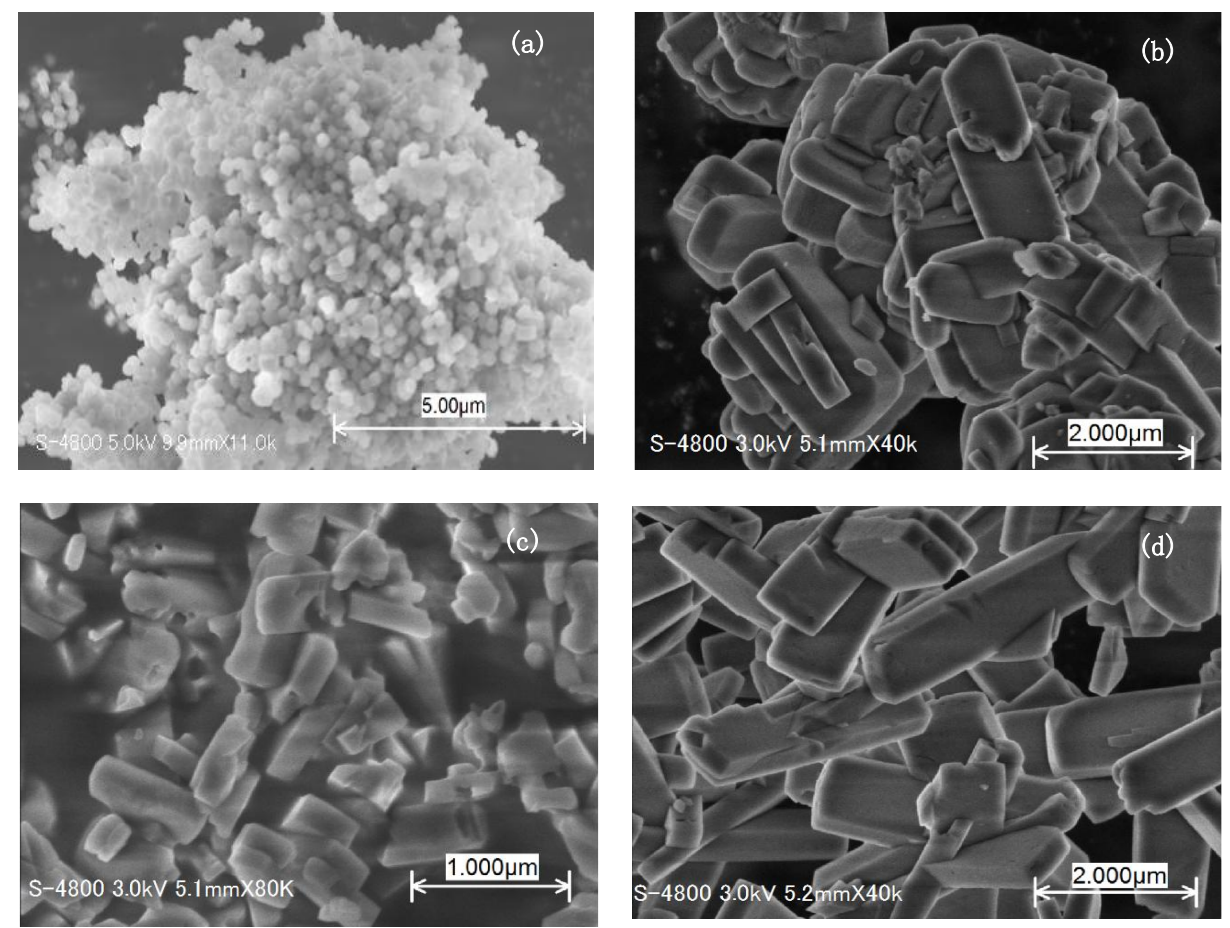

Figure 3. SEM images of (a) MFI-S; (b) MFI-70; (c) MFI-150 and (d) MFI-470.

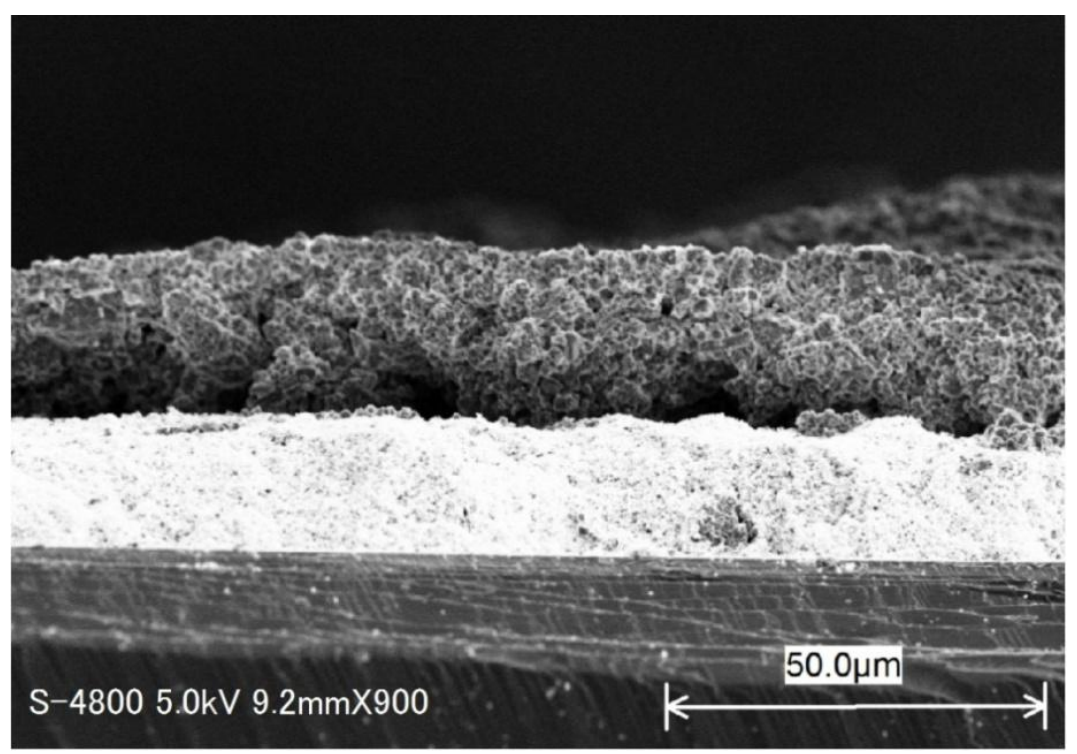

Figure 4. Cross-sectional SEM image for ZSM-5 coated $\mathrm{SnO}_{2}$ sensor.

Table 1. The $\mathrm{SiO}_{2} / \mathrm{Al}_{2} \mathrm{O}_{3}$ ratio and the grain size of four kinds of zeolites.

\begin{tabular}{ccccc}
\hline Zeolite & MFI-S & MFI-70 & MFI-150 & MFI-470 \\
\hline $\mathrm{SiO}_{2} / \mathrm{Al}_{2} \mathrm{O}_{3}$ & 70 & 70 & 150 & 470 \\
$\mathrm{Grain} \mathrm{size}$ & $300 \mathrm{~nm}$ & $\sim 1 \mu \mathrm{m}$ & $\sim 1 \mu \mathrm{m}$ & $\sim 1 \mu \mathrm{m}$ \\
\hline
\end{tabular}




\subsection{Gas Sensing Properties}

Operating temperature is an important parameter for semiconductor gas sensor. Figure 5 illustrates the responses of the $\mathrm{SnO}_{2}$ gas sensor and four kinds of ZSM- 5 zeolites coated $\mathrm{SnO}_{2}$ gas sensors to $10 \mathrm{ppm}$ formaldehyde vs. operating temperature ranged from 250 to $380{ }^{\circ} \mathrm{C}$. The relative humidity (RH) is about $40 \% \mathrm{RH}$. We can see from Figure 5 that the maximum response value to $10 \mathrm{ppm}$ formaldehyde for different sensors appeared at different temperatures. The optimum operating temperature are $350{ }^{\circ} \mathrm{C}$ for MFI-70, MFI- 150 and MFI- 470 coated $\mathrm{SnO}_{2}$ sensors, and the temperature is slightly higher than that of MFI-S coated $\mathrm{SnO}_{2}$ sensor and $\mathrm{SnO}_{2}$ sensor $\left(300{ }^{\circ} \mathrm{C}\right)$. The reasons for these two different optimum operating temperatures may be related to the grain size of zeolites ZSM-5. The heterogeneous catalytic temperature of zeolite has a certain relation with grain size [35]. The smaller the grain size, the lower the catalytic temperature and vice versa. As the grain size of the MFI-S $(\sim 300 \mathrm{~nm})$ is much smaller than that of the other three zeolites $(\sim 1 \mu \mathrm{m})$, so that the optimal operating temperature of the MFI-S coated $\mathrm{SnO}_{2}$ sensor is slightly lower than the latter three.

Figure 5 shows that the maximum response value to $10 \mathrm{ppm}$ formaldehyde of MFI-S coated $\mathrm{SnO}_{2}$ gas sensor (18.6) is higher than that of $\mathrm{SnO}_{2}$ gas sensor (5.8). The optimum operating temperature is $350{ }^{\circ} \mathrm{C}$ for MFI-70, MFI-150 and MFI-470 coated $\mathrm{SnO}_{2}$ sensors, and the temperature is slightly higher than that of MFI-S coated $\mathrm{SnO}_{2}$ sensor and $\mathrm{SnO}_{2}$ sensor.

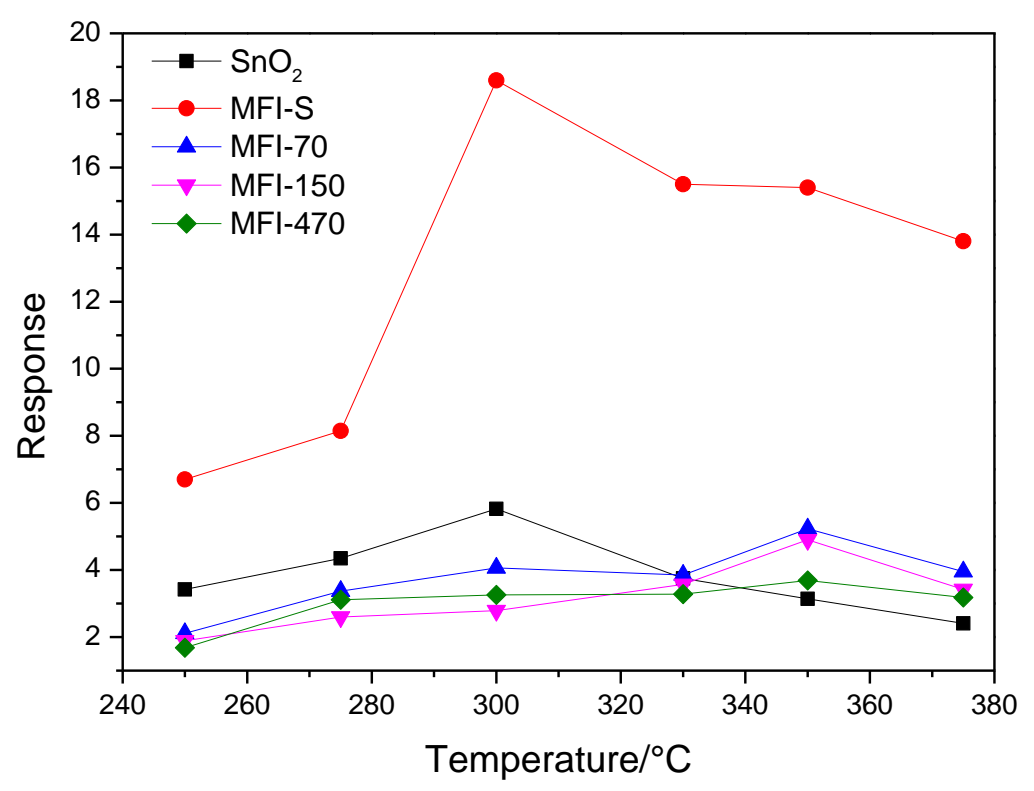

Figure 5. Relationships between sensors response and operating temperature.

The responses of ZSM- 5 coated $\mathrm{SnO}_{2}$ sensors to $10 \mathrm{ppm}$ different VOCs gases are plotted together and compared to the $\mathrm{SnO}_{2}$ sensors' in the bar diagram presented in Figure 6. The VOCs gases include formaldehyde, acetone, toluene, benzene and ammonia. The measurement results show that the ZSM- 5 coated $\mathrm{SnO}_{2}$ sensors have great influence on the responses of formaldehyde and acetone, but have little effect on the responses of toluene, benzene and ammonia. The response values to formaldehyde and acetone are significantly higher than that of toluene, benzene and ammonia, respectively. Table 2 gives the response values of four kinds of $\mathrm{ZSM}-5$ coated $\mathrm{SnO}_{2}$ sensors and $\mathrm{SnO}_{2}$ sensor to $10 \mathrm{ppm}$ formaldehyde, acetone, toluene, benzene and ammonia with a relative humidity $45 \% \mathrm{RH}$, respectively. We find that compared with the $\mathrm{SnO}_{2}$ sensor, the response of MFI-S coated sensor to formaldehyde increased from 3.5 to 11.0, but acetone decreased from 5.0 to 3.5. However, for ammonia, toluene and benzene vapors, the "coating effect" is not obvious and remains at a relatively low response value (less than 2). This indicates that MFI-S coating indeed improves the selectivity of $\mathrm{SnO}_{2}$ gas sensor to formaldehyde against acetone, toluene, benzene and ammonia vapors. Further analysis of the data in 
Figure 6 reveals that the responses of the other three ZSM-5 zeolites (MFI-70, MFI-150, and MFI-470) coated $\mathrm{SnO}_{2}$ sensors to formaldehyde change a little. Although $\mathrm{SiO}_{2} / \mathrm{Al}_{2} \mathrm{O}_{3}$ ratio of the three samples are different, the grain sizes are nearly the same $(\sim 1 \mu \mathrm{m})$. This indicates that the grain size plays more important role than $\mathrm{SiO}_{2} / \mathrm{Al}_{2} \mathrm{O}_{3}$ ratio here. We can also see from Figure 6 that the response of the MFI-S coated sensor to acetone decreases and the other three ZSM- 5 zeolite coated sensors increase in a small scale compared with the $\mathrm{SnO}_{2}$ sensor. Comparing the responses of $\mathrm{SnO}_{2}$ and MFI-S coated $\mathrm{SnO}_{2}$ gas sensors to formaldehyde and acetone, we can conclude that the interference from acetone was very little when formaldehyde was detected by using the MFI-S coated $\mathrm{SnO}_{2}$ sensor.

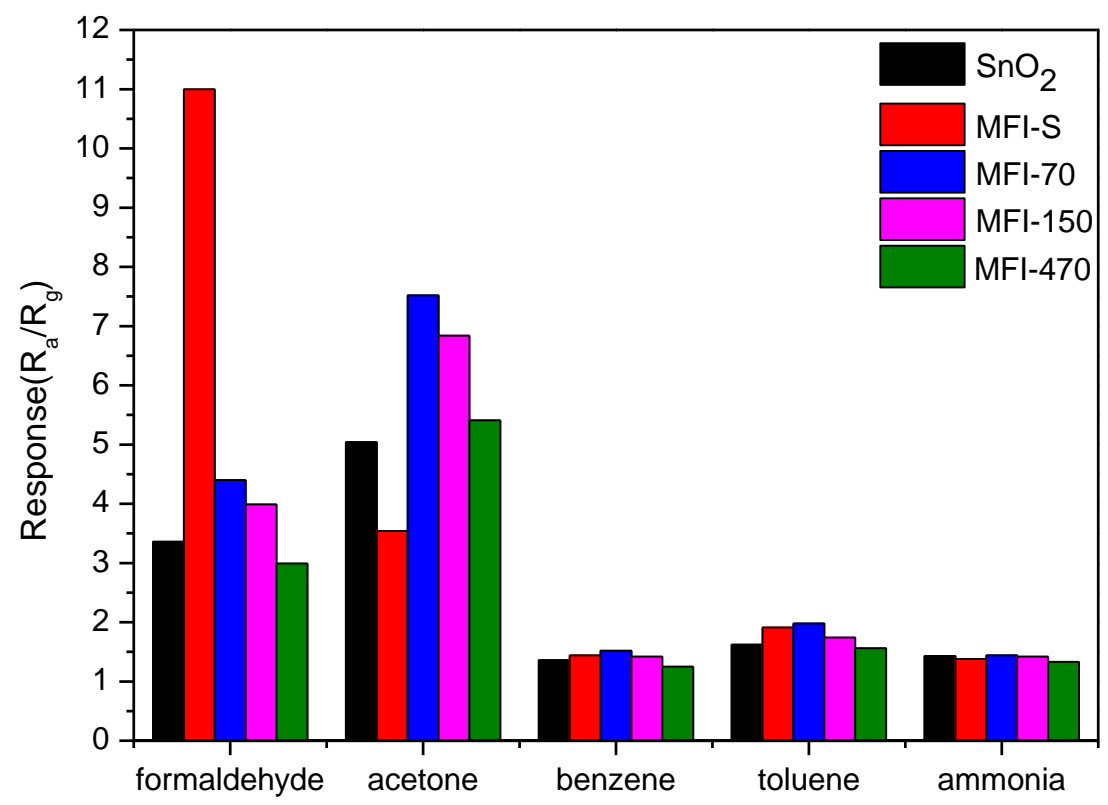

Figure 6. Responses of ZSM-5 coated $\mathrm{SnO}_{2}$ sensors and $\mathrm{SnO}_{2}$ sensors to different gases in $45 \% \mathrm{RH}$.

Table 2. The response values of $\mathrm{SnO}_{2}$ gas sensor and $\mathrm{ZSM}-5$ zeolites coated $\mathrm{SnO}_{2}$ sensors to gases with a relative humidity $45 \% \mathrm{RH}$.

\begin{tabular}{cccccc}
\hline Sensor & $\begin{array}{c}\mathbf{1 0} \mathbf{~ p p m} \\
\text { Formaldehyde }\end{array}$ & $\begin{array}{c}\mathbf{1 0} \mathbf{~ p p m} \\
\text { Acetone }\end{array}$ & $\begin{array}{c}\mathbf{1 0} \mathbf{~ p p m} \\
\text { Benzene }\end{array}$ & $\begin{array}{c}\mathbf{1 0} \mathbf{~ p p m} \\
\text { Toluene }\end{array}$ & $\begin{array}{c}\mathbf{1 0} \mathbf{~ p p m} \\
\text { Ammonia }\end{array}$ \\
\hline $\mathrm{SnO}_{2}$ & 3.5 & 5.0 & 1.4 & 1.6 & 1.4 \\
MFI-S coated $\mathrm{SnO}_{2}$ & 11.0 & 3.5 & 1.4 & 1.9 & 1.4 \\
MFI-70 coated $\mathrm{SnO}_{2}$ & 4.4 & 7.5 & 1.5 & 2.0 & 1.4 \\
MFI-150 coated $\mathrm{SnO}_{2}$ & 4.0 & 6.8 & 1.4 & 1.7 & 1.4 \\
MFI-470 coated $\mathrm{SnO}_{2}$ & 3.0 & 5.4 & 1.3 & 1.6 & 1.3 \\
\hline
\end{tabular}

Figure 7 illustrates the responses of $\mathrm{SnO}_{2}$ and $\mathrm{ZSM}-5$ coated $\mathrm{SnO}_{2}$ gas sensors to formaldehyde in a concentration range of $2 \sim 50 \mathrm{ppm}$ with a relative humidity 50\% RH. We can see from Figure 7 that the response of MFI-S coated $\mathrm{SnO}_{2}$ sensors to formaldehyde is much higher than that of $\mathrm{SnO}_{2}$ in this concentration range and the response value reached 17 for 50 ppm formaldehyde. We can also find from the figure that the sensitivities (slope of the curves) for these sensors are different. The sensitivity in low concentration range is higher than that in high concentration range, especially for MFI-S coated $\mathrm{SnO}_{2}$ sensor. This is because the amount of gas molecules which adsorbed on sensitive materials increased with the rising of target gas concentration. The sensor's response value increased rapidly, leading to a higher sensitivity. However, the adsorption saturates gradually with the increase of gas concentration, the response value increases slow subsequently, and the sensitivity become small. The gas saturation concentration is different for different sensing materials. The saturation 
concentration of the MFI-S coated $\mathrm{SnO}_{2}$ sensor is the highest in these sensors. With the increase of zeolitic $\mathrm{SiO}_{2} / \mathrm{Al}_{2} \mathrm{O}_{3}$ ratio, the response value and sensitivity of this type sensors decrease gradually.

Figure 8 shows the transient response curves of the MFI-S coated $\mathrm{SnO}_{2}$ gas sensor to formaldehyde. The concentration of formaldehyde ranged from $2 \mathrm{ppm}$ to $50 \mathrm{ppm}$, the operating temperature was $300{ }^{\circ} \mathrm{C}$ and the relative humidity was $50 \% \mathrm{RH}$.

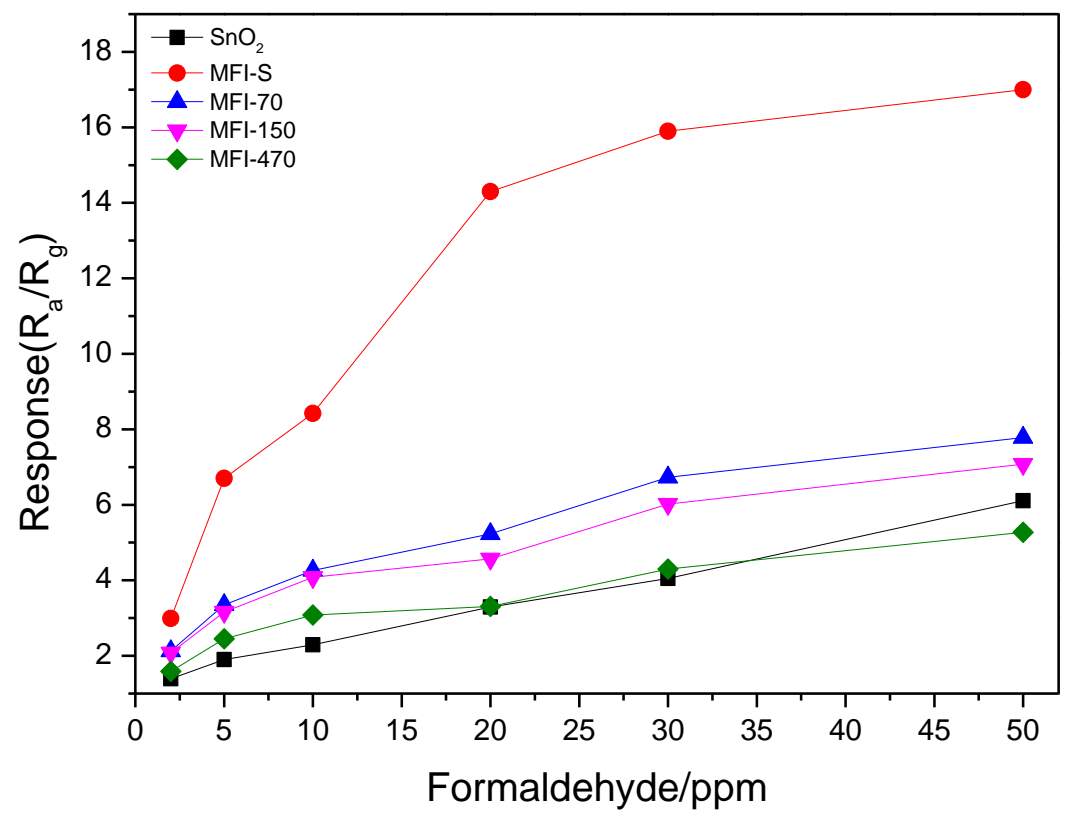

Figure 7. Sensors responses vs. concentration to formaldehyde.

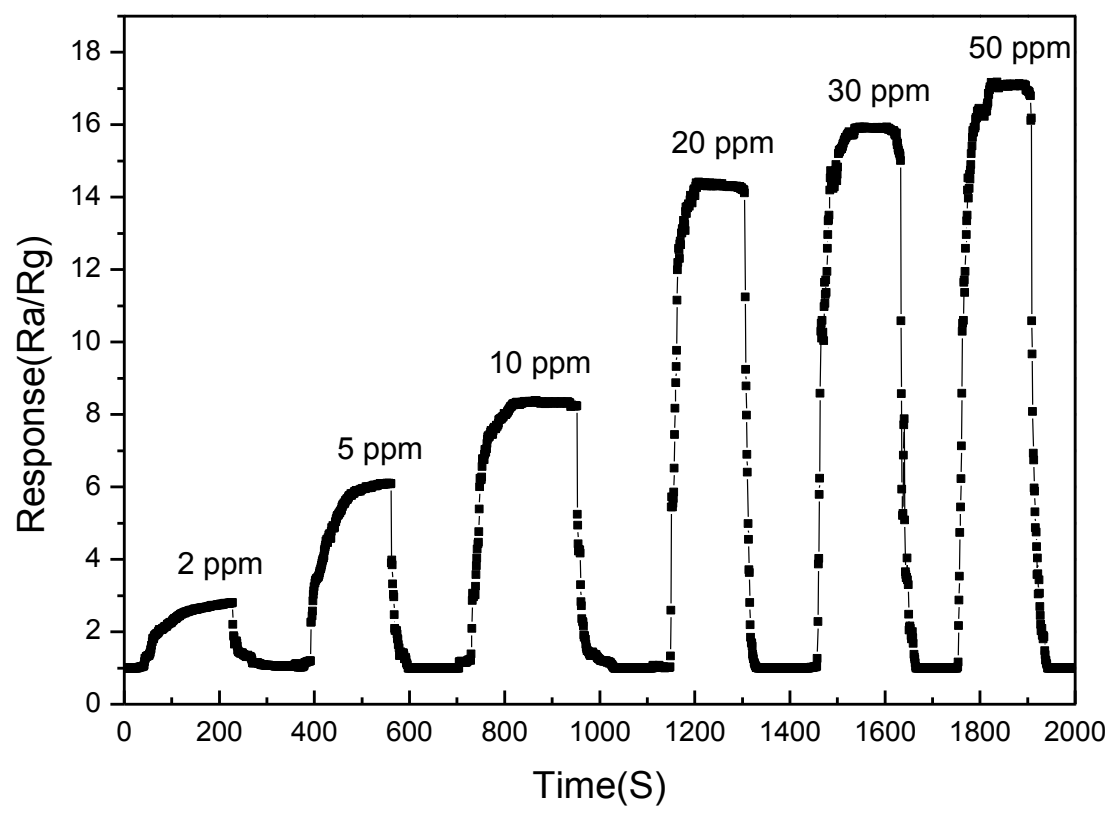

Figure 8. Transient response curves of the MFI-S coated $\mathrm{SnO}_{2}$ gas sensors to formaldehyde.

Figure 9 gives the transient response and recovery properties of $\mathrm{SnO}_{2}$ and MFI-S coated $\mathrm{SnO}_{2}$ sensors to $10 \mathrm{ppm}$ formaldehyde. The response and recovery times of MFI-S coated $\mathrm{SnO}_{2}$ sensor was a little longer than $\mathrm{SnO}_{2}$ sensor which were $50 \mathrm{~s}$ and $36 \mathrm{~s}, 88 \mathrm{~s}$ and $65 \mathrm{~s}$, respectively. The response and recovery times were defined as the times reaching $90 \%$ of the final values. This may be due to the fact that the response value of the MFI-S coated $\mathrm{SnO}_{2}$ sensor is higher than the one of $\mathrm{SnO}_{2}$ sensor, resulting 
in longer response and recovery times. Meanwhile, the added zeolite layer delayed the arrival time of the target gas reach to the sensitive material $\left(\mathrm{SnO}_{2}\right)$, and also affected the gas desorption time.

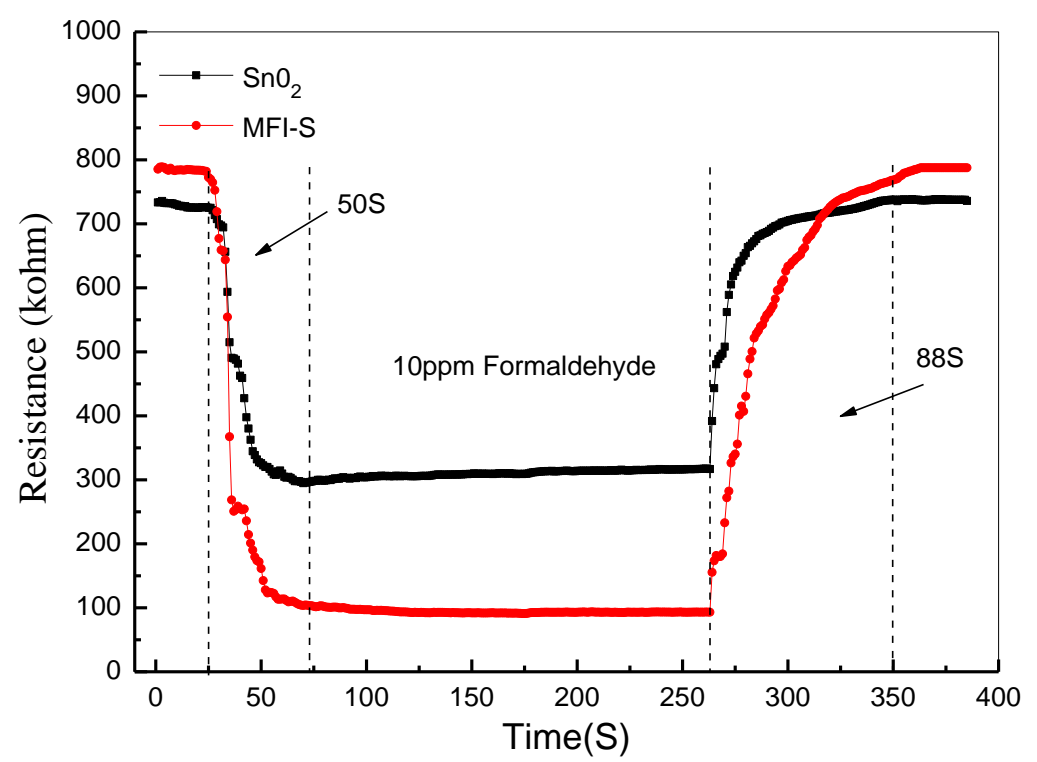

Figure 9. Transient response and recovery properties of $\mathrm{SnO}_{2}$ and MFI-S coated $\mathrm{SnO}_{2}$ sensors to 10 ppm formaldehyde.

Humidity is one of important influencing factors to properties of both zeolite and metal oxide. Figure 10 shows the response curves of MFI-S coated $\mathrm{SnO}_{2}$ sensor to different concentration formaldehyde in humidity of $20 \% \mathrm{RH}$ and $50 \% \mathrm{RH}$, respectively. The response value of the MFI-S coated $\mathrm{SnO}_{2}$ sensors decreases with the increase of relative humidity, especially in high concentration range. This indicates that the additional water vapor seriously impacts the response value of the sensor to formaldehyde. The response values of the MFI-S coated $\mathrm{SnO}_{2}$ are 101 and 17 for $50 \mathrm{ppm}$ formaldehyde in relative humidity of $20 \% \mathrm{RH}$ and $50 \% \mathrm{RH}$, respectively.

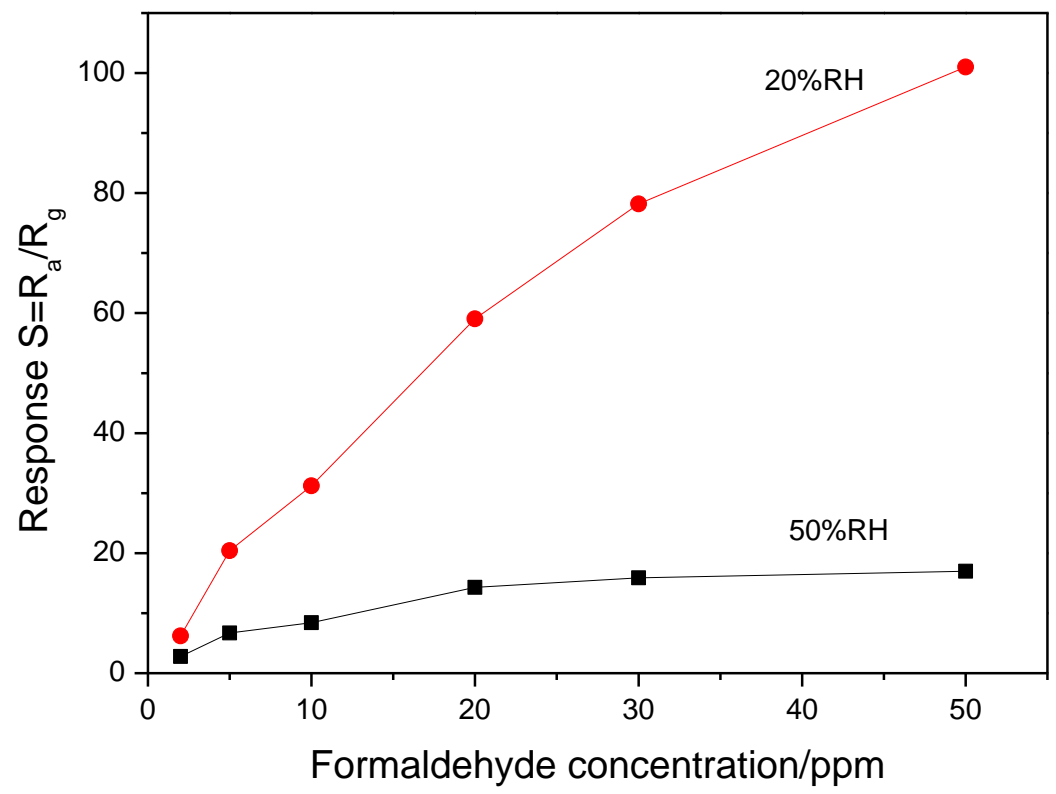

Figure 10. Responses of MFI-S coated sensor to 2-50 ppm formaldehyde in $20 \% \mathrm{RH}$ and $50 \% \mathrm{RH}$. 
We try to analyze this phenomenon as follows: The formaldehyde and acetone sensing processes can be described using the following reactions:

$$
\begin{gathered}
\frac{1}{2} \mathrm{O}_{2(\mathrm{~g})}+\mathrm{e}^{-} \rightarrow \mathrm{O}_{\text {ads }}^{-} \\
\mathrm{HCHO}_{(\text {gas })}+2 \mathrm{O}_{\text {ads }}^{-} \rightarrow \mathrm{CO}_{2}+\mathrm{H}_{2} \mathrm{O}+2 \mathrm{e}^{-} \\
\mathrm{CH}_{3} \mathrm{COCH}_{3 \text { (gas) }}+8 \mathrm{O}_{\text {(ads) }}^{-} \rightarrow 3 \mathrm{CO}_{2}+3 \mathrm{H}_{2} \mathrm{O}+8 \mathrm{e}^{-}
\end{gathered}
$$

We can see from the reaction Equations (1)-(3) that electrons produce as the adsorbed oxygen $\left(\mathrm{O}_{\text {ads }}^{-}\right)$on the surface of the sensing materials reacts with formaldehyde and/or acetone vapor. However, the reaction can be driven back. With the increasing of humidity, more electrons take part in the reaction with water vapor [22,31], which will hinder the forward proceeding of the reaction, causing the increase of the sensor resistance $\left(R_{\mathrm{g}}\right)$ and the decrease of the sensor response. On the other hand, humidity increases some water molecular adsorbed on the $\mathrm{SnO}_{2}$ surface and some of them adsorbed at a place in channel of zeolite which prevents the formaldehyde contact with $\mathrm{SnO}_{2}$ resulting a decreased response [36,37].

\subsection{Gas Sensing Mechanism}

The measurement results show that the response of MFI-S coated $\mathrm{SnO}_{2}$ sensors to formaldehyde increase, meanwhile, the response for acetone vapor decrease, indicating a good selectivity and sensitivity of the sensor to formaldehyde when the disturb gas was acetone. This effect is obvious when the coating materials ZSM-5 zeolite possess small particle size (MFI-S, $300 \mathrm{~nm}$ ). The reason for an increased sensitivity of the sensor was analyzed as follows: The structure of MFI-S coated $\mathrm{SnO}_{2}$ is a layer of ZSM-5 zeolite filter layer covered outside of $\mathrm{SnO}_{2}$. When the sensors are placed in the formaldehyde atmosphere, some gas molecule can pass through the gaps of ZSM-5 layer and contact with $\mathrm{SnO}_{2}$, the others adsorption on internal acidic sites of zeolite. The gaps between crystalline also made gas easier pass through the ZSM-5 layer and contact with $\mathrm{SnO}_{2}$. The acidic sites of zeolites are the catalytic activity center. With the catalytic effect of the zeolite, the reducing gas formaldehyde is oxidized to generate water and other products, and some electrons are released [37]. The electrons are transported to the surface of $\mathrm{SnO}_{2}$, decreasing the resistance of the sensors. This result in an increased response value from 3.0 for $\mathrm{SnO}_{2}$ sensor to 11 for MFI-S coated $\mathrm{SnO}_{2}$ sensor. On the other hand, for large grain size ZSM-5 zeolite ( $1 \mu \mathrm{m}$ : MFI-70, MFI-150 and MFI-470), as the $\mathrm{SiO}_{2} / \mathrm{Al}_{2} \mathrm{O}_{3}$ ratio of the ZSM-5 increases, response value to formaldehyde decrease a little (4.4, 4.0 and 3.0 for MFI-70, MFI-150 and MFI-470). This may result from the number of acidic sites in ZSM-5 zeolites decreasing with the increase in $\mathrm{SiO}_{2} / \mathrm{Al}_{2} \mathrm{O}_{3}$ ratio, and the catalytic activity of the zeolite weakening [38]. At the same time, the crystalline size of ZSM-5 zeolites is a very important factor for increasing response value of the sensor to formaldehyde. The smaller the zeolite particle size is, the larger the specific surface area, and therefore the higher the catalytic activity [39].

It can be found that MFI-S (small grain size, low $\mathrm{SiO}_{2} / \mathrm{Al}_{2} \mathrm{O}_{3}$ ratio ZSM-5 zeolite) can effectively improve the response values of sensitive materials to formaldehyde by analyzing gas sensing properties of this type of sensor. Table 3 lists some similar structure of materials' sensing properties to formaldehyde vapor. We find that response value of the MFI-S coated $\mathrm{SnO}_{2}$ sensor was higher than other sensors when comparing the sensing properties of the sensors in the list. The MFI-S could play an important role in this sensing process. Therefore, the MFI-S coated $\mathrm{SnO}_{2}$ sensor is promising to be used in the detection of low concentration of formaldehyde in the future, and this method (adding MFI-S layer) provides a possible new strategy to improve the response values of sensitive materials to formaldehyde gas detection. 
Table 3. The comparison on sensing properties of some similar structures sensors for formaldehyde gas detection.

\begin{tabular}{|c|c|c|c|c|c|}
\hline Type & Structures of the Sensing Materials & $\begin{array}{l}\text { Response Value (Concentration, } \\
\text { Relative Humidity) }\end{array}$ & $\begin{array}{c}\text { Operating } \\
\text { Temperature }\left({ }^{\circ} \mathrm{C}\right)\end{array}$ & Response Time (s) & Recovery Time (s) \\
\hline Obtained materials & MFI-S coated $\mathrm{SnO}_{2}$ & $11.0(10 \mathrm{ppm}, 45 \% \mathrm{RH})$ & 300 & 50 & 88 \\
\hline \multirow{2}{*}{ Zeolite/metal oxide composite } & $\begin{array}{l}\mathrm{ZnO} \text { and zeolitic imidazolate framework-8 } \\
\text { core-shell heterostructures [16] }\end{array}$ & 13.0 (100 ppm,50\% RH) & 300 & 16 & 9 \\
\hline & Zeolitic imidazolate framework [40] & 13.9 (100 ppm, <70\% RH) & 150 & $\sim 100$ & $\sim 120$ \\
\hline \multirow[t]{2}{*}{$\begin{array}{l}\text { Hierarchical porous } \\
\text { nanostructures }\end{array}$} & Hierarchical porous nanostructures of $\mathrm{SnO}_{2}$ [41] & $\sim 8.0(10 \mathrm{ppm})$ & 330 & 4.03 & - \\
\hline & $\mathrm{Au} @ \mathrm{SnO}_{2}$ core-shell structure [42] & $2.9(50 \mathrm{ppm}, 50 \% \mathrm{RH})$ & room temperature & 80 & 62 \\
\hline \multirow{9}{*}{$\begin{array}{l}\mathrm{SnO}_{2} \text { and other oxides } \\
\text { doped/heterostructures }\end{array}$} & NiO-doped $\mathrm{SnO}_{2}$ nanofiber [43] & $6.3(10 \mathrm{ppm})$ & 200 & 50 & 80 \\
\hline & $1 \mathrm{D} \mathrm{NiO}-\mathrm{SnO}_{2}$ nanofibers [44] & $1.2(20 \mathrm{ppm})$ & 275 & - & - \\
\hline & $\mathrm{SnO}_{2} / \mathrm{In}_{2} \mathrm{O}_{3}$ hetero-nanofiber [9] & $7.5(10 \mathrm{ppm})$ & 375 & $\sim 50$ & $\sim 70$ \\
\hline & MWCNTs-doped $\mathrm{SnO}_{2}[45]$ & $\sim 1.5(10 \mathrm{ppm})$ & 250 & $>100$ & $>90$ \\
\hline & $\mathrm{Zn}_{2} \mathrm{SnO}_{4} / \mathrm{SnO}_{2}$ cubes [46] & $19.98(20 \mathrm{ppm})$ & 200 & 66 & 27 \\
\hline & $\mathrm{SnO}_{2} / \mathrm{ZnO}$ nanofibers [47] & $\sim 4.0(50 \mathrm{ppm})$ & 350 & - & - \\
\hline & $\begin{array}{l}\text { 3D center-hollow architecture and polyporous } \\
\left.\text { surface } \mathrm{SnO}_{2}-\mathrm{ZnO} \text { composites [ } 48\right]\end{array}$ & $\sim 2(10 \mathrm{ppm})$ & room temperature & - & - \\
\hline & Cd-Doped $\mathrm{TiO}_{2}-\mathrm{SnO}_{2}[49]$ & $32(200 \mathrm{ppm})$ & 320 & 25 & 17 \\
\hline & Antimony-Doped $\mathrm{SnO}_{2}$ nanoparticles [50] & $\sim 7.0(10 \mathrm{ppm})$ & 136 & - & - \\
\hline
\end{tabular}


The differences of the response values between the $\mathrm{ZSM}-5$ coated $\mathrm{SnO}_{2}$ and $\mathrm{SnO}_{2}$ gas sensors to acetone were not obvious (Figure 6). The response values of the $\mathrm{ZSM}-5$ coated $\mathrm{SnO}_{2}$ sensors to acetone appear different changes: compared with the $\mathrm{SnO}_{2}$ sensor, the response increases little for MFI-70, MFI-150 and MFI-470 coated $\mathrm{SnO}_{2}$ sensors, and decreases a small amount for MFI-S coated $\mathrm{SnO}_{2}$ sensors. Zeolite possesses both molecular sieve and catalytic properties. From the results of this experiment, catalytic property may play an important act at the large grain size zeolites $(\sim 1 \mu \mathrm{m}$ : MFI-70, MFI-150 and MFI-470), resulting an increasing response; sieve property may play main role for small grain size zeolite (MFI-S, $300 \mathrm{~nm}$ ), leading to a decreased response. The mechanism of zeolite in $\mathrm{SnO}_{2}$ sensing to $\mathrm{VOC}$ gases needs further investigation.

\section{Conclusions}

ZSM-5 zeolite with $300 \mathrm{~nm}$ grain size and ratio of $\mathrm{SiO}_{2} / \mathrm{Al}_{2} \mathrm{O}_{3}=70$ was prepared by using the template method. MFI-S and three other zeolites with grain size $\sim 1 \mu \mathrm{m}$ and ratio of $\mathrm{SiO}_{2} / \mathrm{Al}_{2} \mathrm{O}_{3} 70$, 150 and 470 (MFI-70, MFI-150 and MFI-470) coated $\mathrm{SnO}_{2}$ gas sensors were fabricated, respectively. Their gas sensing properties were tested and compared with that of the $\mathrm{SnO}_{2}$ gas sensor. The results showed that the response value of MFI-S coated $\mathrm{SnO}_{2}$ gas sensors to formaldehyde vapor were obviously increased, and the response to acetone decreased compared with that of the pure $\mathrm{SnO}_{2}$ gas sensor, indicating an improved selectivity property. The other three ZSM-5 zeolites (MFI-70, MFI-150 and MFI-470, grain sizes all around $1 \mu \mathrm{m}$ ) coated with $\mathrm{SnO}_{2}$ sensors do not show much difference compared to the $\mathrm{SnO}_{2}$ sensor for the response properties to both formaldehyde and acetone. This indicates that the zeolite grain size in the $\mathrm{ZSM}-5$ coated $\mathrm{SnO}_{2}$ sensors plays a crucial role. Humidity has a significant effect on the responses of the MFI-S zeolite coated $\mathrm{SnO}_{2}$ gas sensors. As humidity increases, the response of the sensor decreases obviously. The response and recovery times of the MFI-S coated $\mathrm{SnO}_{2}$ sensor was a little longer than the $\mathrm{SnO}_{2}$ sensor which was $50 \mathrm{~s}$ and $36 \mathrm{~s}, 88 \mathrm{~s}$ and $65 \mathrm{~s}$, respectively. The grain sizes of ZSM-5 zeolites are a very important factor for increasing response value of the sensor to formaldehyde.

Acknowledgments: The authors thank The National Natural Science Foundation of China $(61574025,61501081$, 51602035 and 61474012) and Fundamental Research Funds for the Central Universities (DC201501062) for financial supports.

Author Contributions: Yanhui Sun, Jing Wang and Xiaogan Li conceived and designed the experiments, Yanhui Sun, Haiying Du and Qingpan Huang performed the experiments; Jing Wang, Yanhui Sun and Xiaofeng Wang analyzed the gas sensing mechanism.

Conflicts of Interest: The authors declare no conflict of interest.

\section{References}

1. Kawamura, K.; Kerman, K.; Fujihara, M.; Nagatani, N.; Hashiba, T.; Tamiya, E. Development of a novel hand-held formaldehyde gas sensor for the rapid detection of sick building syndrome. Sens. Actuators B Chem. 2005, 105, 495-501. [CrossRef]

2. Manoonkitiwongsa, P.S.; Schultz, R.L. Proper nomenclature of formaldehyde and paraformaldehyde fixatives for histochemistry. Histochem. J. 2001, 34, 365-367.

3. Koziel, J.A.; Noah, J.; Pawliszyn, J. Field sampling and determination of formaldehyde in indoor air with solid-phase microextraction and on-fiber derivatization. Environ. Sci. Technol. 2001, 35, 1481-1486. [CrossRef] [PubMed]

4. Suzuki, Y.; Nakano, N.; Suzuki, K. Portable sick house syndrome gas monitoring system based on novel colorimetric reagents for the highly selective and sensitive detection of formaldehyde. Environ. Sci. Technol. 2003, 37, 5695-5700. [CrossRef] [PubMed]

5. Lee, J.-H. Gas sensors using hierarchical and hollow oxide nanostructures: Overview. Sens. Actuators B Chem. 2009, 140, 319-336. [CrossRef]

6. DU, H.-Y.; Wang, J.; WU, N. Improvement of gas sensing-characteristics of formaldehyde gas sensor by doping. Instrum. Tech. Sens. 2009, 74, 378-383. 
7. Zheng, W.; Lu, X.; Wang, W.; Dong, B.; Zhang, H.; Wang, Z.; Xu, X.; Wang, C. A rapidly responding sensor for methanol based on electrospun $\mathrm{In}_{2} \mathrm{O}_{3}-\mathrm{SnO}_{2}$ nanofibers. J. Am. Ceram. Soc. 2010, 93, 15-17. [CrossRef]

8. Chiu, H.-C.; Yeh, C.-S. Hydrothermal synthesis of $\mathrm{SnO}_{2}$ nanoparticles and their gas-sensing of alcohol. J. Phys. Chem. C 2007, 111, 7256-7259. [CrossRef]

9. Du, H.-Y.; Wang, J.; Su, M.; Yao, P.; Zheng, Y.; Yu, N. Formaldehyde gas sensor based on $\mathrm{SnO}_{2} / \mathrm{In}_{2} \mathrm{O}_{3}$ hetero-nanofibers by a modified double jets electrospinning process. Sens. Actuators B Chem. 2012, 166, 746-752. [CrossRef]

10. Zhang, W.; Tian, J.; Wang, Y.A.; Fang, X.; Huang, Y.; Chen, W.; Liu, Q.; Zhang, D. Single porous $\mathrm{SnO}_{2}$ microtubes templated from papilio maacki bristles: New structure towards superior gas sensing. J. Mater. Chem. A 2014, 2, 4543-4550. [CrossRef]

11. Huang, J.; Li, G.; Huang, Z.; Huang, X.; Liu, J. Temperature modulation and artificial neural network evaluation for improving the $\mathrm{CO}$ selectivity of $\mathrm{SnO}_{2}$ gas sensor. Sens. Actuators B Chem. 2006, 114, 1059-1063. [CrossRef]

12. Liewhiran, C.; Tamaekong, N.; Wisitsoraat, A.; Tuantranont, A.; Phanichphant, S. Ultra-sensitive $\mathrm{H}_{2}$ sensors based on flame-spray-made Pd-loaded $\mathrm{SnO}_{2}$ sensing films. Sens. Actuators B Chem. 2013, 176, 893-905. [CrossRef]

13. Jang, B.-H.; Landau, O.; Choi, S.-J.; Shin, J.; Rothschild, A.; Kim, I.-D. Selectivity enhancement of $\mathrm{SnO}_{2}$ nanofiber gas sensors by functionalization with $\mathrm{Pt}$ nanocatalysts and manipulation of the operation temperature. Sens. Actuators B Chem. 2013, 188, 156-168. [CrossRef]

14. Yimlamai, I.; Niamlang, S.; Chanthaanont, P.; Kunanuraksapong, R.; Changkhamchom, S.; Sirivat, A. Electrical conductivity response and sensitivity of ZSM-5, Y, and mordenite zeolites towards ethanol vapor. Ionics 2011, 17, 607-615. [CrossRef]

15. Hernández, P.T.; Hailes, S.; Parkin, I. Hydrocarbon detection with metal oxide semiconducting gas sensors modified by overlayer or admixture of zeolites Na-A, H-Y and H-ZSM-5. Sens. Actuators B Chem. 2017, 242, 1281-1295. [CrossRef]

16. Tian, H.; Fan, H.; Li, M.; Ma, L. Zeolitic imidazolate framework coated ZnO nanorods as molecular sieving to improve selectivity of formaldehyde gas sensor. ACS Sens. 2015, 1, 243-250. [CrossRef]

17. Zheng, Y.; Li, X.; Dutta, P.K. Exploitation of unique properties of zeolites in the development of gas sensors. Sensors 2012, 12, 5170-5194. [CrossRef] [PubMed]

18. Sahner, K.; Hagen, G.; Schönauer, D.; Reiß, S.; Moos, R. Zeolites-Versatile materials for gas sensors. Solid State Ion. 2008, 179, 2416-2423. [CrossRef]

19. Xu, X.; Wang, J.; Long, Y. Zeolite-based materials for gas sensors. Sensors 2006, 6, 1751-1764. [CrossRef]

20. Binions, R.; Afonja, A.; Dungey, S.; Lewis, D.W.; Parkin, I.P.; Williams, D.E. Discrimination effects in zeolite modified metal oxide semiconductor gas sensors. IEEE Sens. J. 2011, 11, 1145-1151. [CrossRef]

21. Varsani, P.; Afonja, A.; Williams, D.E.; Parkin, I.P.; Binions, R. Zeolite-modified $\mathrm{WO}_{3}$ gas sensors-Enhanced detection of $\mathrm{NO}_{2}$. Sens. Actuators B Chem. 2011, 160, 475-482. [CrossRef]

22. Vilaseca, M.; Coronas, J.; Cirera, A.; Cornet, A.; Morante, J.; Santamaria, J. Development and application of micromachined $\mathrm{Pd} / \mathrm{SnO}_{2}$ gas sensors with zeolite coatings. Sens. Actuators B Chem. 2008, 133, 435-441. [CrossRef]

23. Sahner, K.; Schönauer, D.; Moos, R.; Matam, M.; Post, M.L. Effect of electrodes and zeolite cover layer on hydrocarbon sensing with p-type perovskite $\mathrm{SrTi}_{0.8} \mathrm{Fe}_{0.2} \mathrm{O}_{3-\delta}$ thick and thin films. J. Mater. Sci. 2006, 41, 5828-5835. [CrossRef]

24. Fukui, K.; Nishida, $\mathrm{S}$. $\mathrm{CO}$ gas sensor based on $\mathrm{Au}-\mathrm{La}_{2} \mathrm{O}_{3}$ added $\mathrm{SnO}_{2}$ ceramics with siliceous zeolite coat. Sens. Actuators B Chem. 1997, 45, 101-106. [CrossRef]

25. Sahner, K.; Schönauer, D.; Kuchinke, P.; Moos, R. Zeolite cover layer for selectivity enhancement of p-type semiconducting hydrocarbon sensors. Sens. Actuators B Chem. 2008, 133, 502-508. [CrossRef]

26. Jadsadapattarakul, D.; Thanachayanont, C.; Nukeaw, J.; Sooknoi, T. Improved selectivity, response time and recovery time by [010] highly preferred-orientation silicalite-1 layer coated on $\mathrm{SnO}_{2}$ thin film sensor for selective ethylene gas detection. Sens. Actuators B Chem. 2010, 144, 73-80. [CrossRef]

27. Yang, P.; Lau, C.; Liang, J.Y.; Lu, J.Z.; Liu, X. Zeolite-based cataluminescence sensor for the selective detection of acetaldehyde. Luminescence 2007, 22, 473-479. [CrossRef] [PubMed]

28. Haw, J.F. Zeolite acid strength and reaction mechanisms in catalysis. Phys. Chem. Chem. Phys. 2002, 4, 5431-5441. [CrossRef] 
29. Konno, H.; Tago, T.; Nakasaka, Y.; Watanabe, G.; Masuda, T. Characterization and catalytic performance of modified nano-scale ZSM-5 for the acetone-to-olefins reaction. Appl. Catal. A Gen. 2014, 475, 127-133. [CrossRef]

30. Viswanadham, N.; Kamble, R.; Singh, M.; Kumar, M.; Dhar, G.M. Catalytic properties of nano-sized ZSM-5 aggregates. Catal. Today 2009, 141, 182-186. [CrossRef]

31. Vilaseca, M.; Coronas, J.; Cirera, A.; Cornet, A.; Morante, J.; Santamaria, J. Use of zeolite films to improve the selectivity of reactive gas sensors. Catal. Today 2003, 82, 179-185. [CrossRef]

32. Xu, X.; Wang, J.; Long, Y. Nano-tin dioxide/NaY zeolite composite material: Preparation, morphology, adsorption and hydrogen sensitivity. Microporous Mesoporous Mater. 2005, 83, 60-66. [CrossRef]

33. $\mathrm{Xu}, \mathrm{D}$. Preparation and Investigation on Properties of Hierarchical Porous Nano-Molecular Sieves. Ph.D. Thesis, Jilin University, Jilin, China, 2011.

34. Du, H.-Y.; Wang, J.; Yu, P.; Yu, N.-S.; Sun, Y.-H.; Tian, J.-L. Investigation of gas sensing materials tin oxide nanofibers treated by oxygen plasma. J. Nanopart. Res. 2014, 16, 1-10. [CrossRef]

35. Yang, H. The Effect of Crystal Size on Selective Catalytic Reduction of NOx by Acetylene over Zeolites. Master's Thesis, Dalian University of Technology, Dalian, China, 2007.

36. Vilaseca, M.; Coronas, J.; Cirera, A.; Cornet, A.; Morante, J.R.; Santamaria, J. Gas detection with $\mathrm{SnO}_{2}$ sensors modified by zeolite films. Sens. Actuators B Chem. 2007, 124, 99-110. [CrossRef]

37. Trimboli, J.; Dutta, P.K. Oxidation chemistry and electrical activity of Pt on titania: Development of a novel zeolite-filter hydrocarbon sensor. Sens. Actuators B Chem. 2004, 102, 132-141. [CrossRef]

38. Xiao, L. Preparation and Catalytic Properties of SnO2 with Different Morphologies. Master's Thesis, Nanchang University, Nanchang, China, 2014.

39. Shetti, V.N.; Kim, J.; Srivastava, R.; Choi, M.; Ryoo, R. Assessment of the mesopore wall catalytic activities of MFI zeolite with mesoporous/microporous hierarchical structures. J. Catal. 2008, 254, 296-303. [CrossRef]

40. Chen, E.X.; Yang, H.; Zhang, J. Zeolitic imidazolate framework as formaldehyde gas sensor. Inorg. Chem. 2014, 53, 5411-5413. [CrossRef] [PubMed]

41. Xu, K.; Zeng, D.; Tian, S.; Zhang, S.; Xie, C. Hierarchical porous $\mathrm{SnO}_{2}$ micro-rods topologically transferred from tin oxalate for fast response sensors to trace formaldehyde. Sens. Actuators B Chem. 2014, 190, 585-592. [CrossRef]

42. Chung, F.-C.; Wu, R.-J.; Cheng, F.-C. Fabrication of a Au@SnO 2 core-shell structure for gaseous formaldehyde sensing at room temperature. Sens. Actuators B Chem. 2014, 190, 1-7. [CrossRef]

43. Zheng, Y.; Wang, J.; Yao, P. Formaldehyde sensing properties of electrospun NiO-doped $\mathrm{SnO}_{2}$ nanofibers. Sens. Actuators B Chem. 2011, 156, 723-730. [CrossRef]

44. Tang, W.; Wang, J. 1D NiO-SnO 2 heterojunction nanofibers as acetone sensor. KnE Mater. Sci. 2016, 1, $172-176$. [CrossRef]

45. Wang, J.; Liu, L.; Cong, S.-Y.; Qi, J.-Q.; Xu, B.-K. An enrichment method to detect low concentration formaldehyde. Sens. Actuators B Chem. 2008, 134, 1010-1015. [CrossRef]

46. Tang, W.; Wang, J.; Yao, P.; Li, X. A microscale formaldehyde gas sensor based on $\mathrm{Zn}_{2} \mathrm{Sno}_{4} / \mathrm{Sno}_{2}$ and produced by combining hydrothermal synthesis with post-synthetic heat treatment. J. Mater. Sci. 2013, 49, 1246-1255. [CrossRef]

47. Tang, W. Sensing mechanism of $\mathrm{SnO}_{2} / \mathrm{ZnO}$ nanofibers for $\mathrm{CH}_{3} \mathrm{OH}$ sensors: Heterojunction effects. J. Phys. D Appl. Phys. 2017, 50, 475105. [CrossRef]

48. Jiang, J.; Shi, L.; Xie, T.; Wang, D.; Lin, Y. Study on the gas-sensitive properties for formaldehyde based on $\mathrm{SnO}_{2}-\mathrm{ZnO}$ heterostructure in uv excitation. Sens. Actuators B Chem. 2018, 254, 863-871. [CrossRef]

49. Zeng, W.; Liu, T.; Wang, Z.; Tsukimoto, S.; Saito, M.; Ikuhara, Y. Selective detection of formaldehyde gas using a cd-doped $\mathrm{TiO}_{2}-\mathrm{SnO}_{2}$ sensor. Sensors 2009, 9, 9029-9038. [CrossRef] [PubMed]

50. Wang, Y.D.; Djerdj, I.; Antonietti, M.; Smarsly, B. Polymer-assisted generation of antimony-doped $\mathrm{SnO}_{2}$ nanoparticles with high crystallinity for application in gas sensors. Small 2008, 4, 1656-1660. [CrossRef] [PubMed]

(C) 2018 by the authors. Licensee MDPI, Basel, Switzerland. This article is an open access article distributed under the terms and conditions of the Creative Commons Attribution (CC BY) license (http:/ / creativecommons.org/licenses/by/4.0/). 